\title{
Comparison of the effects of instrument assisted soft tissue mobilization and dry needling on active myofascial trigger points of upper trapezius muscle
}

\author{
Zeinab Ahmadpour Emshi ${ }^{1}$, Farshad Okhovatian ${ }^{1 * \mathbb{D}}$, Marzieh Mohammadi Kojidi ${ }^{1}$, Alireza Akbarzadeh Baghban ${ }^{2}$, \\ Hadi Azimi ${ }^{3}$
}

Received: 22 Apr 2020

Published: 8 May 2021

\section{Abstract}

Background: Myofascial pain syndrome is one of the most common complaints in patients referring to orthopedic treatment centers. The present study aimed to examine the effects of instrument-assisted soft tissue mobilization (IASTM) and dry needling (DN) on active myofascial trigger points (AMTrP) of the upper trapezius muscle (UTM).

Methods: The current study was designed as a randomized clinical trial and a total of 81 patients, aged 18-40 years, with active myofascial trigger points in the upper trapezius muscle were randomly divided into 3 groups: group $1(\mathrm{n}=30)$ received DN treatment, group $2(n=26)$ received IASTM treatment, and group $3(n=25)$ was considered as the control group (no intervention). The numeric pain scale (NPS), pain pressure threshold (PPT), active cervical contra-lateral flexion (ACLF), neck disability index (NDI), and muscle thickness (MT), according to rehabilitative ultrasonic imaging (RUSI), were measured at baseline, immediately after the last session (session 4 in week 2), and 1 month after the last session. The statistical analysis was conducted at a 95\% confidence level. The $\mathrm{P}$ values less than .05 were considered as statistically significant.

Results: Both techniques were effective in treating active trigger point of the upper trapezius $(\mathrm{p}<0.05)$, but there was no significant difference between the treatment groups in terms of any of the above variables except for ACLF $(\mathrm{p}>0.05)$

Conclusion: Both IASTM and DN were determined to improve NPS, PPT, ROM, and NDI in participants with active trigger points in the upper trapezius, although IASTM was more effective in increasing ACLF in these patients.

Keywords: Instrument Assisted Soft Tissue Mobilization Technique, Dry Needling, Active Myofascial Trigger Points, Trapezius Muscle, Myofascial Pain Syndrome

Conflicts of Interest: None declared

Funding: None

*This work has been published under CC BY-NC-SA 1.0 license.

Copyright $\odot$ Iran University of Medical Sciences

Cite this article as: Ahmadpour Emshi Z, Okhovatian F, Mohammadi Kojidi M, Akbarzadeh Baghban A, Azimi H. Comparison of the effects of instrument assisted soft tissue mobilization and dry needling on active myofascial trigger points of upper trapezius muscle. Med J Islam Repub Iran. 2021 (8 May);35:59. https://doi.org/10.47176/mjiri.35.59

\section{Introduction}

Myofascial pain syndrome is one of the most common complaints in patients referring to orthopedic treatment

Corresponding author: Dr Farshad Okhovatian, farshadokhovatian1965@gmail.com

1. Physiotherapy Research Center, School of Rehabilitation, Shahid Beheshti University of Medical Sciences, Tehran, Iran

2. Proteomics Research Center, Department of Biostatistics, School of Allied Medical Sciences, Shahid Beheshti University of Medical Sciences, Tehran, Iran

3. Department of English Language Teaching, School of Medicine, Shahid Beheshti University of Medical Sciences, Tehran, Iran centers (1). About $21 \%$ of people who visit pain clinics suffer from trigger points $(\operatorname{TrP})$. In fact, these points are

$\uparrow$ What is "already known" in this topic:

In today's modern society, trigger points have been considered as the main cause of musculoskeletal pain. This disease has a significant impact on quality of life. Therefore, it should be considered as an important part of treatment in the comprehensive neck physiotherapy program.

\section{$\rightarrow$ What this article adds:}

The aim of this study was to compare the effects of 2 methods of DN technique and IASTM technique in the treatment of active trigger points of the upper trapezius muscle, which helps to improve treatment in patients with myofascial pain syndrome caused by active trigger points. 
Table 1. Inclusion and Exclusion Criteria

$$
\text { Inclusion Criteria }
$$

1. Age between $18-40 \mathrm{y}$

2. Presence of active trigger points in the upper trapezius muscle

3. Pain intensity of at least $30 \mathrm{~mm}$ in the numeric pain scale

2. History of head, neck, cervical spine or shoulder surgery

3. History of cervical radiculopathy

4. Diagnosed fibromyalgia and myopathy

5. History of cancer

6. Pregnancy Myofascial therapy within the past month

7. Contraindication of dry needling and instrument-assisted soft tissue mobilization technique

the primary sources of musculoskeletal pains in $30 \%$ to $85 \%$ of patients and a major cause of back and neck pains (2). With the growing prevalence of modern sedentary lifestyle, the role of trigger points as a major cause of musculoskeletal pains has drawn more attention among researchers (3). Indeed, the high prevalence of trigger point involvement and the am ount of money spent every year to alleviate the symptoms of this condition are strong motivations for closer attention to this subject. Naturally, the goal of research in this area is to find a treatment with high efficacy and lasting effects (4).

Instrument assisted soft tissue mobilization (IASTM) is a popular therapeutic approach for myofascial restrictions. IASTM is based on the rationale introduced by James Cyriax, but instead of cross friction massage with fingers, it involves using specially designed steel instruments to create controlled micro trauma in the soft tissue (eg, scar tissue, myofascial adhesion) with the purpose of reducing pain and improving the range of motion (ROM) and function $(5,6)$.

The growing interest in this technique as a treatment approach for myofascial pain syndrome can partly be attributed to its remarkable effects on muscle tissues and surrounding fascia. There is evidence suggesting that a controlled microtrauma created during soft tissue mobilization enhances the tissue repair process by stimulating the proliferation of fibroblasts (7).

There is currently much controversy about the effect of dry needling on myofascial pain. In some studies, this effect has been reported to be positive, but in some cases, the treatment was not successful and the results did not differ from those of the placebo. In addition, there has been no study reporting comparison of these 2 treatments. The purpose of the present study was to hopefully find results that are more definitive in the treatment of AMTrp.

The present study aimed to compare the effects of IASTM and dry needling in the treatment of active myofascial trigger points (AMTrP) of the upper trapezius to contribute to the ongoing progress in the treatment of TrPinduced myofascial pain syndrome.

In the present study, it was hypothesized that the therapeutic effects of IASTM and DN techniques could lead to a further decrease in NPS, MT, and NDI scales as well as a further increase in PPT and ACLF scales compared to the control group.

\section{Methods}

\section{Study Population}

Participants were selected using simple nonrandom availability sampling from among all the students at the
School of Rehabilitation, Shahid Beheshti University of Medical Sciences, Tehran. Potential participants were invited via public announcements and the volunteers who met the inclusion criteria and had active trigger points in the upper trapezius muscle were enlisted.

After explaining the treatment methods and conditions to the potential participants, informed consent was obtained, and then the inventory of demographic information, body mass index, and inclusion/exclusion criteria was completed by the examiner. The inclusion and exclusion criteria for the present study are listed in Table $1(8$, 9). Those who did not complete the treatment, did not return for the follow-up, or used other treatment and analgesics during the study were also excluded. The present study was designed as a randomized clinical trial and registered in the Iranian Registry of Clinical Trials (Code No. RCT20180311039049N1). The present study has been approved by the ethics committee of Shahid Beheshti University of Medical Sciences (Code No. IR.SBMU.RETECH.REC.1396.278).

\section{General Study Design}

The general study design is illustrated in a flowchart (Fig. 1). The study was conducted on a total of 81 participants who were randomly divided into 3 groups. Using the data collected from the studies of Segura-orti et al and Jong et al $(10,11)$ and considering a type-I error of $\alpha=0.5$ and type-II error of 0.2 , the appropriate sample size was calculated to be 25 per group ( 75 in total). This calculation was performed using PASS Sample Size Software. In this study, a sample of 75 people, 25 cards for each intervention group and 25 cards for control group were considered and placed inside a sealed envelope that is nontransparent to draw. Then, each patient takes one of the cards randomly and their group is identified and the generated sequence is recorded. Data were analyzed using SPSS software (V16). Normality of data was investigated using ShapiroWilk test at the $\mathrm{p}>0.05$ significance level. A 1-way analysis of variance was run to determine whether there was a difference among the 3 groups regarding age, BMI (Body Mass Index), and BDI (Beck Depression Inventory) and all 5-outcome measures (NPS, PPT, ACLF, NDI, and MT) at baseline. For multiple comparisons, a Tukey procedure was used.

\section{Outcome Measures}

Numeric Pain Scale (NPS): NPS is a $10-\mathrm{cm}$ line that patients can use to rate the intensity of their pain on a scale of 0 to $10(0=$ no pain; $10=$ maximum pain $)$. In our study, patients were asked to rate their pain on this scale as the 


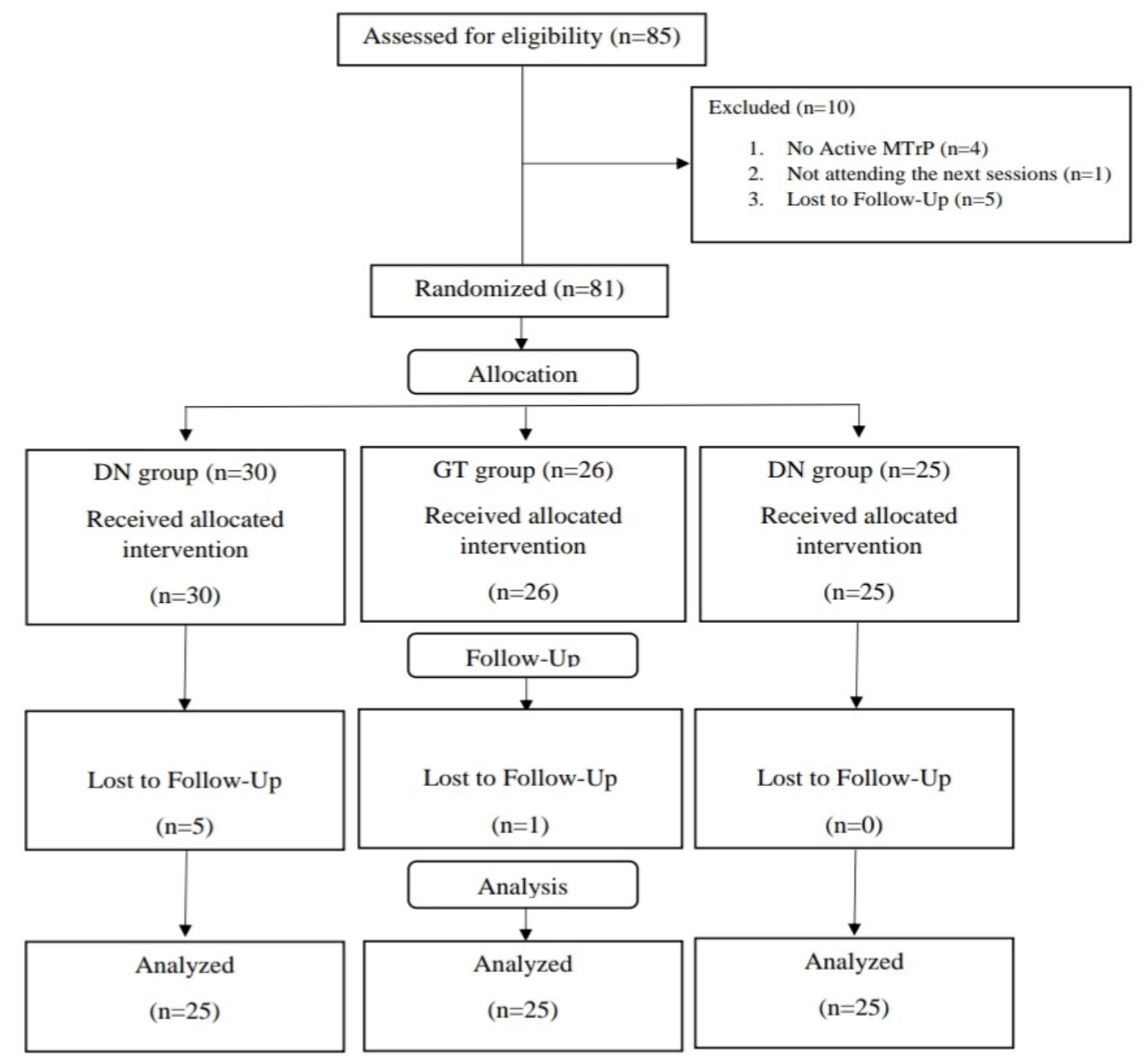

Fig. 1. Flow diagram of the control trial

examiner gradually exerted pressure on the trigger point. For this measurement, the patient was asked to seat on a chair in a relaxed position with the neck in a neutral posture and arms hanging normally at the side of the body $(12,13)$.

Pressure Pain Threshold (PPT): The measurements of PPT and pain level were performed using an algometer (Lutron 5020, Taiwan), with an accuracy of 0.01 (Fig. 2). For this measurement, the patient was guided to seat on a chair in a relaxed position with the hands hanging next to the body. The algometer was pressed perpendicularly to the most sensitive trigger point at a rate of about $1 \mathrm{~kg} / \mathrm{cm}^{2}$ until the patient reported pain sensation. The applied force at that moment was recorded and the point of pressure was marked. These measurements were performed 3 times with 40 -second rests and the results were averaged (12, 14).

Note that in another study, the interrater and intrarater reliabilities of the examiners' measurements of active cervical contralateral flexion with goniometer and measurements of PPT in the upper trapezius with algometer were assessed in a group of 20 healthy young women. For this assessment, the 2 examiners made the aforementioned measurements 3 times at 60 -second intervals and repeated these measurements after 1 hour. For PPT, the intraclass correlation coefficient (ICC) was calculated to be 0.928 for the first examiner and 0.000 for the second examiner, and the interrater reliability coefficient was calculated to be 0.742 (for the first measurement), which fall in the category of good reproducibility (reliability), according to Rossner's classification.

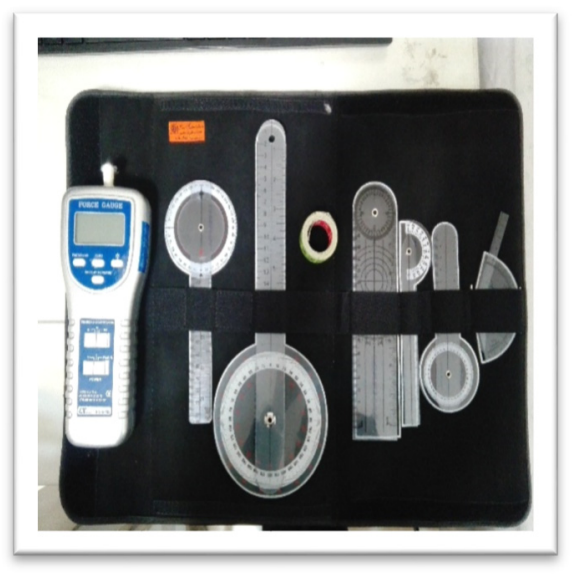

Fig. 2. Measurement set (goniometer and algometer) 
Active Cervical Contralateral Flexion (ACLF): CROM (Beck Depression Inventory) has a high inter- and intraexaminer reliability for measuring lateral cervical bending (ICC $=0.84$ and 0.96 respectively) (15). In the study mentioned previously, the intrarater reliability of ACLF measurement was 0.985 (first examiner, first measurement) and its interrater reliability was 0.969 (first measurement), which signify excellent intrarater and interrater reliability indices. ACLF was measured using a transparent plastic goniometer (Fig. 1). For this measurement, the patient was asked to sit straight on a chair. The base of the goniometer was placed on the spinous process of the first thoracic vertebra, the center of its vertical arm was placed on occipital protuberance at the right angle, the transverse arm was manually fixed, and the vertical arm was moved with occipital protuberance to measure the angle of contralateral flexion of the neck. The patient was asked to bend his/her neck laterally (get the ear close to the shoulder without raising the shoulder). This measurement was made 3 times with 30 -second rests and the results were averaged (8).

Neck Disability Index (NDI): Introduced by Howard Vernon in 1989, Neck Disability Index (NDI) is a standard tool for measuring the level of disability caused by neck pain. This questionnaire consists of 10 sections, each containing 6 items, which are scored from 0 to 5 . Thus, the total score of this questionnaire ranges from 0 to 50 . This questionnaire has been translated into Persian and localized by Mousavi et al (2007) at the University of Tehran who have verified the validity and reliability of the translated instrument (16). In the present study, the level of neck disability was measured using the Persian version of the NDI questionnaire.

Muscle Thickness (MT): Muscle thickness was measured using a Honda 2100 ultrasound machine with a linear probe of 5 centimeter in length and frequency of $7.5 \mathrm{MHz}$ This measurement was made in 2 ways as described below.

The First Method: The patient was asked to lie in prone position with the head and neck in neutral postures. The shoulders were supported via towels to prevent shoulder belt protraction. A medium-size pillow was placed under the patient's abdomen to reduce lumbar lordosis. The patient's arms were resting beside the body with the palms facing up (Fig. 3). The ultrasound probe was positioned on the spinous process of the sixth cervical vertebra and then moved obliquely along the body curvature until observing the triangular-shaped junction of fascia and muscle on the monitor screen. Then, the probe was moved outward to observe the mass of the upper trapezius muscle. Muscle thickness at the musculofascial junction was measured using the software Image $\mathrm{J}$ by placing the cursor on the inner edge of the border of the muscle at the position specified in RUSI (17).

The Second Method: The patient was asked to seat in a relaxed position. The spinous process of the seventh cervical vertebra and the acromion were identified and the midpoint of the direct line between these points was marked (external landmark). The probe was placed centrally on the mark and moved horizontally until the trian-

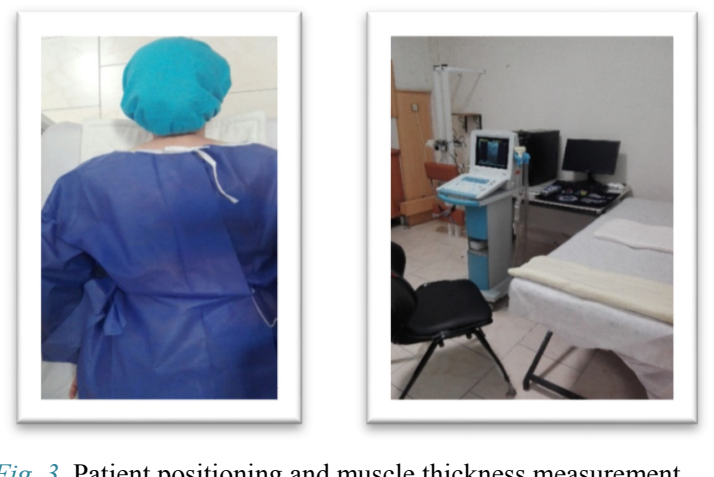

Fig. 3. Patient positioning and muscle thickness measurement

gular-shaped junction of supraspinatus muscle with upper trapezius came into view. This was considered as the position of maximum muscle thickness (internal landmark).

\section{Interventions}

Dry Needling: Dry needling was performed by a certified therapist who took all necessary precautions, including sterilizing the position with cotton and alcohol, wearing disposable gloves, and placing needles of different patients in separate containers.

For this procedure, the patient was asked to lie in prone position with arms resting naturally beside the body. The therapist identified the tight muscle bands and used the thumb and index finger of the other hand to grab the band for easier needling and feeling of local twitch responses (LTR). The needle was inserted into the trigger points at a 30-degree angle using the fanning technique. The needle was repeatedly pulled out and reinserted into another part of the trigger point at a different angle until no LTR was felt (10). Only 1 trigger point was treated at each session. This treatment was performed 2 sessions per week for 2 weeks (4 sessions in total) (Fig. 4).

Soft Tissue Mobilization With Myo-Release (Fig. 5): For IASTM, skin surface was heated by an infrared light for 5 minutes to increase the blood flow and muscle tissue temperature and then the muscle tissue was massaged using the myo-release tool for 5 minutes. The tool used in this procedure was the myo-release No.1 (manufactured in Iran) made of stainless steel (Fig. 6). Immediately after the massage, the therapist applied 3 passive stretches on the

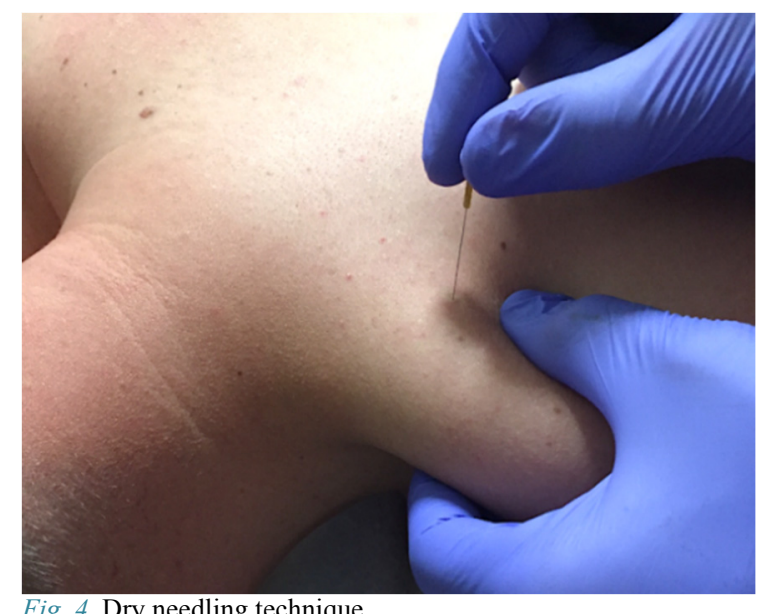

Fig. 4. Dry needling technique 


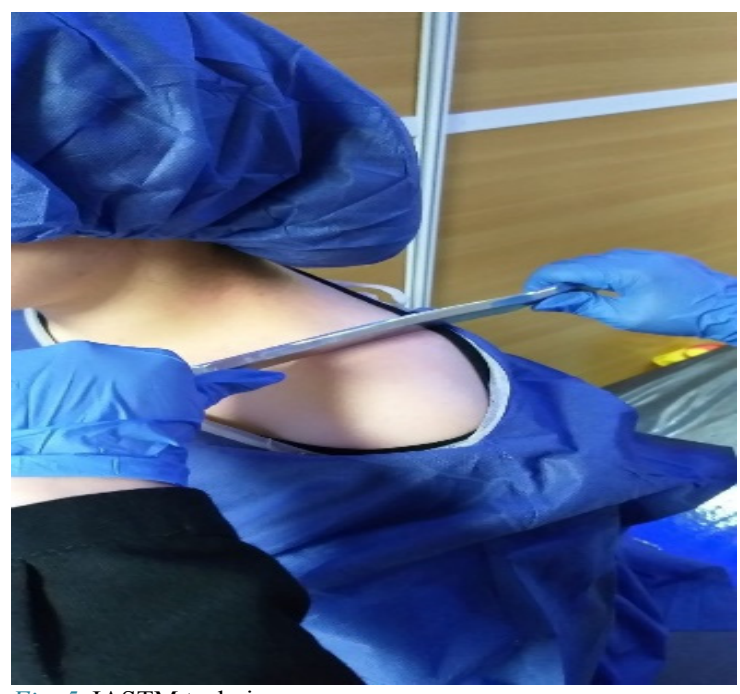

Fig. 5. IASTM technique

muscle for 30 seconds. This was followed by the patient performing 2 sets of 12 active muscle stretches and lastly performing the shoulder lifting exercise in 2 sets of 15 . The treatment was performed 2 sessions per week for 2 weeks (4 sessions in total) (18).

The massage with myo-release consisted of the following steps (19):

1- One minute of sweeping the upper trapezius region (longitudinal strokes performed parallel to the muscle fibers);

2- One minute of swiveling directly over the AMTrP (the knob of the tool was placed directly on the AMTrP and pivoted/rotated back and forth);

3- Two minutes of fanning the AMTrP and surrounding tissues in all directions (a stroke in which one end of the instrument is held in place and the other end is moved in a fan-shaped pattern); and finally

4- Another one minute of sweeping the upper trapezius region.

\section{Control Group}

In the present study, the control group received no treatment until after the final examinations at the followup stage (the end of the study), at which point they received free physiotherapy sessions. It should be noted that none of the participants had a history of treatment for painful neck spots in the preceding month and all participants were fully aware of research design and participated after signing informed consent.

\section{Results}

This study was conducted on a total of 81 participants, 4 males and 77 females, who were randomly divided into 3 groups: (i) Graston technique ( $\mathrm{n}=26$ ), (ii) dry needling $(n=30)$, and (iii) control group $(n=25)$. First, one-way ANOVA was used to compare the groups at the baseline. Table 2 presents the results of the one-way ANOVA (analysis of variance) on the participants' demographic and anthropometric characteristics. As shown, the obtained probability statistics were all higher than .05 , which confirmed the homogeneity of the groups in terms of these variables. The results of the chi-square test also showed no significant difference between the 3 groups in terms of the dominant side of treatment (right or left side of the body) $(\mathrm{p}=0.923)$ and gender $(\mathrm{p}=0.290)$.

Given the detection of a difference between the groups in terms of NPS and MT at baseline, this comparison was

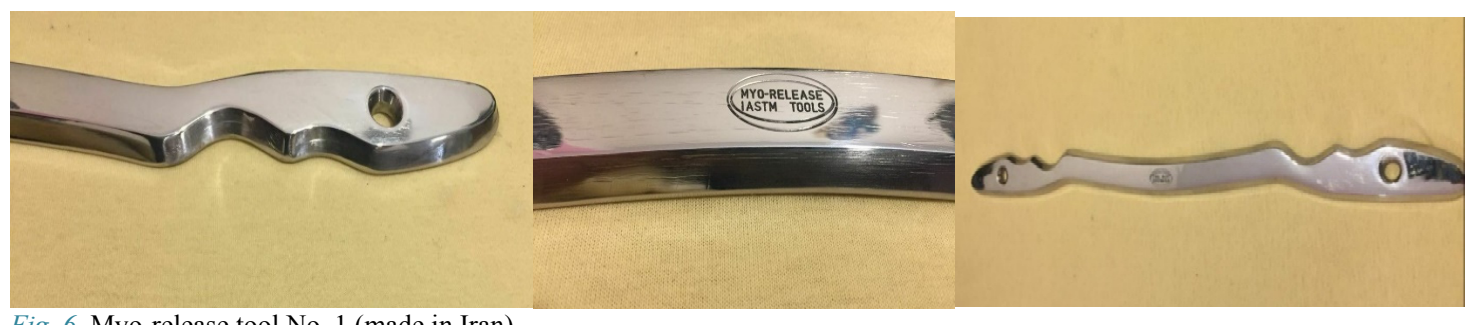

Fig. 6. Myo-release tool No. 1 (made in Iran)

\begin{tabular}{|c|c|c|c|c|c|c|}
\hline Variables & $\begin{array}{c}\text { Intervention } \\
\text { Groups }\end{array}$ & Mean & $\mathrm{SD}^{I}$ & $\overline{\operatorname{Min}^{2}}$ & $\operatorname{Max}^{3}$ & $\mathrm{p}$ \\
\hline \multirow{3}{*}{ Age } & $\mathrm{GT}$ & 26.50 & 5.72 & 20 & 40 & \multirow{3}{*}{0.174} \\
\hline & $\mathrm{DN}$ & 29.63 & 6.77 & 21 & 40 & \\
\hline & $\mathrm{CG}$ & 27.48 & 6.49 & 19 & 40 & \\
\hline \multirow{3}{*}{ Height } & GT & 1.62 & 0.07 & 1.53 & 1.82 & \multirow{3}{*}{0.081} \\
\hline & $\mathrm{DN}$ & 1.62 & 0.04 & 1.53 & 1.70 & \\
\hline & CG & 1.66 & 0.08 & 1.57 & 1.92 & \\
\hline \multirow{3}{*}{ Weight } & GT & 59.05 & 8.38 & 45.00 & 79.00 & \multirow{3}{*}{0.058} \\
\hline & DN & 64.75 & 11.64 & 48.00 & 96.00 & \\
\hline & $\mathrm{CG}$ & 66.56 & 14.15 & 45.00 & 96.00 & \\
\hline \multirow{3}{*}{ BMI } & GT & 22.41 & 2.91 & 17.96 & 28.30 & \multirow{3}{*}{0.115} \\
\hline & $\mathrm{DN}$ & 24.52 & 3.97 & 18.06 & 36.13 & \\
\hline & CG & 24.09 & 4.59 & 17.99 & 36.13 & \\
\hline \multirow{3}{*}{ BDI } & GT & 11.08 & 8.56 & 0 & 34 & \multirow{3}{*}{0.633} \\
\hline & $\mathrm{DN}$ & 13.80 & 10.39 & 0 & 45 & \\
\hline & $\mathrm{CG}$ & 12.72 & 12.65 & 0 & 48 & \\
\hline
\end{tabular}

${ }^{1}$ Standard deviation

${ }^{2}$ Minimum

${ }^{3}$ Maximum 


\begin{tabular}{|c|c|c|c|c|c|c|c|c|c|c|c|c|}
\hline Variable & Group & $\begin{array}{c}\text { Mean } \\
\text { /SD }\end{array}$ & $\begin{array}{l}\text { Before } \\
\text { the } \\
\text { First } \\
\text { Session } \\
\end{array}$ & $\begin{array}{l}\text { After } \\
\text { the } \\
\text { First } \\
\text { Session }\end{array}$ & $\begin{array}{l}\text { After } \\
\text { the } \\
\text { Fourth } \\
\text { Session }\end{array}$ & FU & $\begin{array}{c}\text { P Value } \\
\text { Baseline } \\
\quad(3 \\
\text { groups }) \\
\end{array}$ & $\begin{array}{c}\text { P Value } \\
\text { After } 2 \\
\text { Weeks } \\
\text { (3groups) }\end{array}$ & $\begin{array}{c}\text { P Value } \\
\text { Baseline } \\
\text { (GT\&DN) }\end{array}$ & $\begin{array}{l}\text { P Value } \\
\text { after the } \\
\text { First } \\
\text { Session } \\
\text { (GT\&DN) }\end{array}$ & $\begin{array}{l}\text { P Value } \\
\text { after the } \\
\text { Fourth } \\
\text { Session } \\
\text { (GT\&DN) }\end{array}$ & $\begin{array}{c}\text { P Value } \\
\text { FU } \\
\text { (GT\&DN) }\end{array}$ \\
\hline \multirow{6}{*}{ NPS } & GT & Mean & 5.65 & 3.42 & 1.46 & 0.92 & \multirow{6}{*}{0.001} & \multirow{6}{*}{$<0.001$} & \multirow{6}{*}{0.005} & \multirow{6}{*}{0.388} & \multirow{6}{*}{0.198} & \multirow{6}{*}{0.604} \\
\hline & & $\mathrm{SD}$ & 1.49 & 1.85 & 1.63 & 1.70 & & & & & & \\
\hline & $\mathrm{DN}$ & Mean & 6.82 & 4.23 & 2.28 & 1.52 & & & & & & \\
\hline & & $\mathrm{SD}$ & 1.40 & 2.23 & 1.62 & 1.96 & & & & & & \\
\hline & $\mathrm{CG}$ & Mean & 5.28 & - & 5.60 & - & & & & & & \\
\hline & & $\mathrm{SD}$ & 1.59 & - & 1.95 & - & & & & & & \\
\hline \multirow{5}{*}{ PPT } & GT & Mean & 11.11 & 10.66 & 11.91 & 12.22 & \multirow{6}{*}{0.113} & \multirow{5}{*}{$<0.001$} & \multirow{5}{*}{0.053} & \multirow{5}{*}{0.182} & \multirow{5}{*}{0.112} & \multirow{5}{*}{0.001} \\
\hline & & $\mathrm{SD}$ & 3.64 & 3.70 & 3.25 & 3.96 & & & & & & \\
\hline & $\mathrm{DN}$ & Mean & 9.42 & 8.55 & 10.37 & 10.51 & & & & & & \\
\hline & & $\mathrm{SD}$ & 2.71 & 2.24 & 2.41 & 2.43 & & & & & & \\
\hline & $\mathrm{CG}$ & Mean & 10.85 & - & 9.59 & - & & & & & & \\
\hline \multirow{7}{*}{ ROM } & & $\mathrm{SD}$ & 3.33 & - & 2.72 & - & & \multirow{7}{*}{$<0.001$} & \multirow{7}{*}{0.382} & \multirow{7}{*}{0.045} & \multirow{7}{*}{0.145} & \multirow{7}{*}{0.006} \\
\hline & GT & Mean & 41.26 & 45.07 & 48.27 & 47.26 & \multirow{6}{*}{0.608} & & & & & \\
\hline & & $\mathrm{SD}$ & 7.65 & 7.07 & 6.76 & 8.35 & & & & & & \\
\hline & $\mathrm{DN}$ & Mean & 39.60 & 42.38 & 44.99 & 44.00 & & & & & & \\
\hline & & $\mathrm{SD}$ & 6.42 & 8.73 & 6.08 & 7.34 & & & & & & \\
\hline & $\mathrm{CG}$ & Mean & 41.29 & - & 40.56 & - & & & & & & \\
\hline & & $\mathrm{SD}$ & 7.74 & - & 6.32 & - & & & & & & \\
\hline & GT & Mean & 23.55 & - & 22.39 & 21.66 & & & & & & \\
\hline & & $\mathrm{SD}$ & 5.56 & - & 5.06 & 4.38 & & & & & & \\
\hline MT & $\mathrm{DN}$ & Mean & 17.93 & - & 17.34 & 17.02 & $<0.001$ & 0.239 & 0.001 & 0.099 & 0.239 & 0.028 \\
\hline & & SD & 3.73 & - & 3.01 & 2.00 & & & & & & \\
\hline & $\mathrm{CG}$ & Mean & 17.78 & - & 17.47 & - & & & & & & \\
\hline & & $\mathrm{SD}$ & 2.32 & - & 1.93 & - & & & & & & \\
\hline & GT & Mean & 41.71 & - & 38.35 & 36.10 & & & & & & \\
\hline & & $\mathrm{SD}$ & 9.04 & - & 9.06 & 7.35 & & & & & & \\
\hline Max-T & $\mathrm{DN}$ & Mean & 37.08 & - & 34.50 & 34.47 & 0.126 & 0.066 & 0.069 & 0.838 & $>0.001$ & 0.166 \\
\hline & & $\mathrm{SD}$ & 9.32 & - & 9.12 & 8.76 & & & & & & \\
\hline & $\mathrm{CG}$ & Mean & 38.15 & - & 38.64 & - & & & & & & \\
\hline & & $\mathrm{SD}$ & 6.86 & - & 7.66 & - & & & & & & \\
\hline & GT & Mean & 12.38 & - & 8.35 & 6.80 & & & & & & \\
\hline & & $\mathrm{SD}$ & 6.91 & - & 7.69 & 7.04 & & & & & & \\
\hline NDI & $\mathrm{DN}$ & Mean & 13.28 & - & 8.21 & 7.36 & 0.656 & 0.013 & 0.618 & 0.584 & $>0.001$ & 0.001 \\
\hline & & $\mathrm{SD}$ & 6.25 & - & 5.69 & 5.73 & & & & & & \\
\hline & $\mathrm{CG}$ & Mean & 11.68 & - & 10.20 & - & & & & & & \\
\hline & & $\mathrm{SD}$ & 5.97 & - & 6.15 & - & & & & & & \\
\hline & GT & Mean & 78.23 & - & 45.81 & 40.60 & & & & & & \\
\hline & & SD & 34.81 & - & 41.64 & 39.50 & & & & & & \\
\hline NPDS & $\mathrm{DN}$ & Mean & 81.00 & - & 46.93 & 39.08 & 0.690 & 0.002 & 0.759 & 0.765 & $>0.001$ & 0.001 \\
\hline & & $\mathrm{SD}$ & 31.83 & - & 34.29 & 32.50 & & & & & & \\
\hline & $\mathrm{CG}$ & Mean & 73.28 & - & 62.08 & - & & & & & & \\
\hline & & $\mathrm{SD}$ & 32.30 & - & 30.80 & - & & & & & & \\
\hline
\end{tabular}

repeated with ANCOVA (analysis of covariance) to control the effect of these differences. The results of this test are reported in Table 3 (columns 4 and 8). The data obtained after the fourth session showed statistically significant differences between the 2 treatment groups and the control group in terms of NPS, PPT, ROM, NDI, and NPDS (Neck Pain and Disability Scale) (see columns 6 and 9 of Table 3) (Chart 1).

\section{Comparison of the Treatment Groups}

After assessing the homogeneity of the treatment groups before the intervention and since we found significant differences between the groups in terms of NPS and MT at baseline, the repeated-measures ANOVA was performed to take the difference of these 2 variables into account (column 10 of Table 3 ). The results of repeated measures ANOVA showed that the only significant difference between the 2 treatment groups was cervical contralateral flexion ROM after the first session (column 11 of Table 3). Both groups also showed statistically significant increases in PPT and ROM and decreases in MT, NDI, and NPDS (column 13 of Table 3 ). The results also showed the lasting effect of both treatments in the followup stage (columns 7 and 13 of Table 3) (Chart 2).

According to the evidence in (columns 4 and 6 of Table 3 ), no improvement in patients' symptoms was observed in the control group after 2 weeks.

Also, Spearman correlation analysis was run to investigate the relationship between NDI and depression index (BDI). The results of this investigation $(r=0.5 ; \mathrm{p}<0.001)$ showed a significant positive correlation between NDI and BDI, which means one increases as the other increases.

\section{Discussion}

The literature has only witnessed a few articles which have compared the short, medium, and long-term effects of IASTM and dry needling on active trigger points of the upper trapezius. The following provides an overview of the studies that have used any of these methods in com-

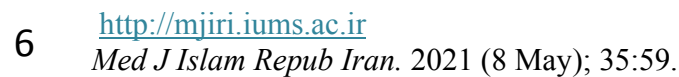




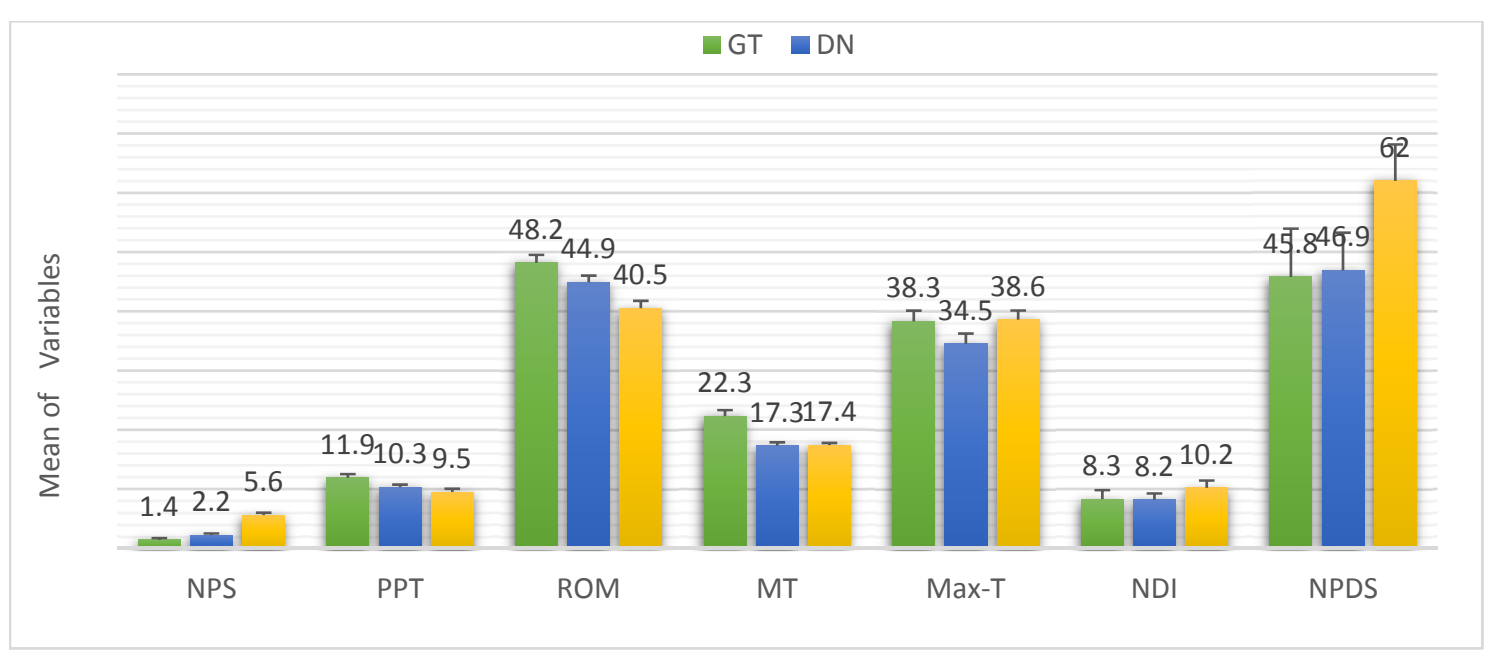

Chart 1. Mean Value of Variables in the 3 groups Immediately After the End of Interventions (GT-DN-CG)

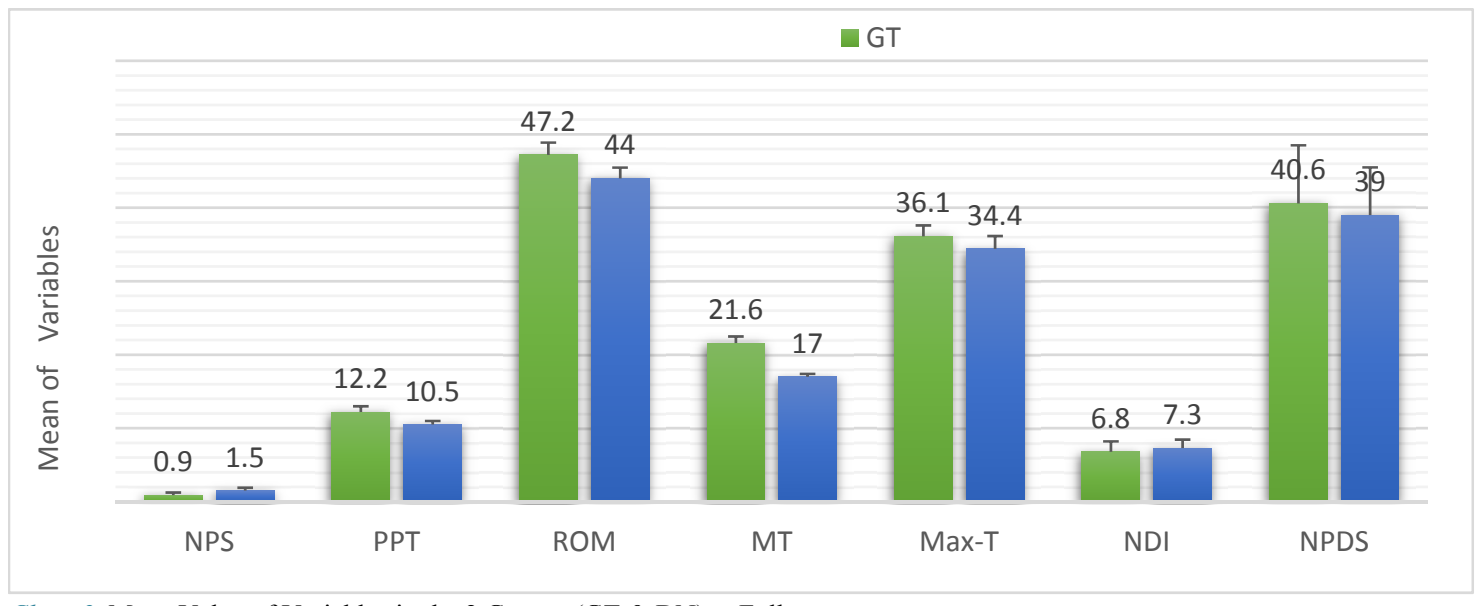

Chart 2. Mean Value of Variables in the 2 Groups (GT \& DN) at Follow-up

parison with each other or with other treatments.

Based on the evidence available to date, dry needling can cautiously be recommended for pain relief in myofascial trigger points in the neck and shoulder (short and medium-term effects). Although dry needling has shown acceptable efficacy in reducing pain in trigger points, its mechanism of effect is still unclear (20). It has been suggested that this mechanism could be hyperstimulation analgesia through the descending inhibitory system (21). Others believe that this treatment works by reducing the spontaneous electrical activity of trigger points (22). According to another hypothesis, which is based on the pain gate control theory, dry needling limits the transmission of pain impulses by inhibiting the $\mathrm{C}$ fibers, a process driven by the activation of A-delta fibers (23). Also, this procedure can disrupt the contraction nodes in the tightened muscle bands; also, it increases the length of shortened sarcomeres and reduces the overlap between actin and myosin filaments, which would help the muscle to return to its normal length and function $(24,25)$.

Also, the existing evidence suggests that IASTM reduces the local pain intensity, increases the pressure pain threshold, the muscle tissue flexibility, and the ROM of the massaged muscle, and alters the neural activities (in 2- point discrimination). IASTM is a unique method that, based on the available evidence, enables therapists to effectively and efficiently identify and treat soft-tissue injuries and musculofascial tissue involvements. When combined with proper exercises, this method can result in painless restoration of muscle ROM and function. It also affects the soft tissue by creating a controlled microtrauma, which some studies suggest will improve the tissue repair by stimulating the fibroblast proliferation. There is clinical evidence supporting the hypothesis that IASTM increases the mobility of musculofascial tissue and reduces the effects of local ischemia by increasing blood flow to the vessels. There is also evidence suggesting that using tools for soft tissue mobilization reduces the therapist's hand pain and fatigue, thereby enhancing the efficacy and quality of treatment.

The present study used 2 different methods to measure the effect of treatments on the thickness of upper trapezius muscle, but, like previous studies, we could not demonstrate the effect of active trigger points in increasing muscle thickness or the effect of treatments in decreasing this thickness. Therefore, further studies are still needed to confirm this claim.

To date, there have been numerous studies on the effects 
of dry needling, though only a few of them are relevant to the present work. Unlike dry needling, IASTM and its impacts on MTrP have been the subject of only a few clinical trials. In any case, the results of the present study are completely consistent with the existing evidence about both techniques and confirm the effect of both methods in reducing local pain intensity (as measured with NPS) and increasing PPT and ROM. The results obtained from the 1-month follow-up also demonstrated the lasting effect of both treatments on the measured variables.

The findings of the present study are in agreement with those reported by Ga et al (2007) who found that dry needling was effective in reducing pain intensity in the upper trapezius of the elderly, especially when it was combined with dry needling of paraspinal muscles (26). Tsai et al (2010) also reported the positive effect of 1 session of dry needling on pain, PPT, and CROM immediately after treatment (27). In another study, Rayegani et al (2014) compared the effect of dry needling with 10 sessions of routine physiotherapy based on measurements made at 3 stages: pretreatment, week 1 , and week 4 . This study found no significant difference between the effects of these treatments and the researchers concluded that dry needling is the preferred method as it is less expensive and takes less time to conduct (28). Abbaszadeh-Amirdehi et al (2016) reported that 1 session of dry needling on active trigger points can improve the pain intensity and PPT and reduce the activity of sympathetic system and response at the neuromuscular junction (14). In a study by Dogan et al (2019), the effects of dry needling and Kinesio taping were compared and it was found that, although they have similar effects in terms of reducing pain and increasing PPT and ROM, Kinesio taping can be a good alternative for patients who are unwilling to undergo dry needling or cases where dry needling is contraindicated (29). Walsh et al (2019) examined the effects of 3 sessions (one session per week) of dry needling on NDI, pain intensity, and PPT and compared them with the effects of extracorporeal shock wave therapy (ESWT) on the same parameters. This study found no difference between the treatment groups before the intervention, immediately after the first session, and 1 and 3 months after the end of the intervention, and concluded that these methods are equally effective and none can be considered superior over the other $(\mathrm{p}>0.05)$ (30). Gulick (2014) investigated the impact of 6 sessions of 5-minute long IASTM treatment on the AMTrP of the upper back. The study was conducted in 2 phases and only examined the pressure sensitivity, which was measured by an algometer. The posttreatment evaluations of this study showed an increase in PPT (31). In 2018, the same researcher conducted a similar but more detailed study with a larger sample size and a control group and reported that IASTM was indeed effective and increased the pressure pain threshold (19). Based on the findings of the present study, the 2 techniques are not particularly superior to each other, but in situations where the patient is not inclined to the dry needle technique due to its aggressiveness or the patient has contraindications to the dry needle technique, the IASTM technique is recommended.

\section{Study Limitations}

The current study had some limitations that should be considered prior to any generalizations. First, given the invasive nature of dry needling and the length of the study (two weeks for treatment plus 4 weeks for follow-up), it was difficult to attract participants.

Also, the purpose of the study was to examine the effects of treatments on both genders (male and female), and although all announcements had explicitly invited volunteers of both genders, there was a small number of male volunteers. Moreover, because of the length of treatment and follow-up periods, it was not possible to recruit a separate examiner and/or to blind the examiner.

\section{Conclusion}

Findings of the present study suggest that dry needling and soft tissue mobilization with myo-release tool may have similar effects on active trigger points of the upper trapezius muscle, which include reducing the pain intensity (as measured with NPS), increasing the pressure pain threshold, increasing the ROM of cervical contralateral flexion, and decreasing the neck disability index. After reviewing the previous reports in the relevant literature, these findings were found to be consistent with the existing evidence regarding the subject under the study.

In addition, the results of measurements in both treatment groups were significantly different from those in the control group, but were not significantly different from each other in terms of any variable except the ROM of cervical contralateral flexion. The present study had a 1month follow-up period, the results of which demonstrated the long-term effects of both treatments on the studied variables.

\section{Acknowledgement}

We would like to thank the participants and the Physiotherapy Research Center of Shahid Beheshti University of Medical Sciences for their help on this project.

\section{Conflict of Interests}

The authors declare that they have no competing interests.

\section{References}

1. Gerwin RD. Classification, epidemiology, and natural history of myofascial pain syndrome. Curr Pain Headache Rep. 2001 Oct 1;5(5):412-20.

2. Borg-Stein J, Simons DG. Myofascial pain. Arch Phys Med Rehabil. 2002 Mar 1;83:S40-7.

3. Yap EC. Myofascial pain-an overview. Ann Acad Med Singap. 2007 Jan 1;36(1):43

4. Liu L, Huang QM, Liu QG, Ye G, Bo CZ, Chen MJ, Li P. Effectiveness of dry needling for myofascial trigger points associated with neck and shoulder pain: a systematic review and meta-analysis. Arch Phys Med Rehabil. 2015 May 1;96(5):944-55.

5. Thompson J, Crowder L, Le D, Roethele A. Efficacy of instrumentassisted soft tissue mobilization for the treatment of musculotendinous injuries: a systematic review: OPO267. J Orthop Sports Phys Ther. 2018 Jan;48(1).

6. Cheatham SW, Lee M, Cain M, Baker R. The efficacy of instrument assisted soft tissue mobilization: a systematic review. J Can Chiropr Assoc. 2016 Sep;60(3):200.

7. Labodi KK. The Effects of the Graston Technique ${ }^{\circledR}$ on Cases of Chronic Tendinopathy Measured by Diagnostic Ultrasound (Doctoral 
dissertation, North Dakota State University). (2018)

8. Lari AY, Okhovatian F, Sadat Naimi S, Baghban AA. The effect of the combination of dry needling and MET on latent trigger point upper trapezius in females. Man Ther. 2016 Feb 1;21:204-9.

9. Kojidi MM, Okhovatian F, Rahimi A, Baghban AA, Azimi H. The influence of Positional Release Therapy on the myofascial trigger points of the upper trapezius muscle in computer users. J Bodyw Mov Ther. 2016 Oct $1 ; 20(4): 767-73$.

10. Segura-Ortí E, Prades-Vergara S, Manzaneda-Pina L, ValeroMartinez R, Polo-Traverso JA. Trigger point dry needling versus strain-counterstrain technique for upper trapezius myofascial trigger points: a randomised controlled trial. Acupunct Med. 2016 Jun;34(3):171-7.

11. Moon JH, Jung JH, Won YS, Cho HY. Immediate effects of Graston Technique on hamstring muscle extensibility and pain intensity in patients with nonspecific low back pain. J Phys Ther Sci. 2017;29(2):224-7.

12. Ebrahimi R, Taheri N. Pain, Pressure Pain Threshold and Disability Following Ane Session of Dry Needling in Subjects with Active Trigger Points in the Upper Trapezius Muscle. J Res Rehabil Sci. 2016;12(2):76-81. (In Persian)

13. Gemmell H, Miller P, Nordstrom H. Immediate effect of ischaemic compression and trigger point pressure release on neck pain and upper trapezius trigger points: a randomised controlled trial. Clin Chiropract. 2008 Mar 1;11(1):30-6.

14. Abbaszadeh-Amirdehi M, Ansari NN, Naghdi S, Olyaei G, Nourbakhsh MR. Neurophysiological and clinical effects of dry needling in patients with upper trapezius myofascial trigger points. $\mathrm{J}$ Bodyw Mov Ther. 2017 Jan 1;21(1):48-52.

15. Hole DE, Cook JM, Bolton JE. Reliability and concurrent validity of two instruments for measuring cervical range of motion: effects of age and gender. Man Ther. 1995 Nov 1;1(1):36-42.

16. Mousavi SJ, Parnianpour M, Montazeri A, Mehdian H, Karimi A, Abedi M, Ashtiani AA, Mobini B, Hadian MR. Translation and validation study of the Iranian versions of the Neck Disability Index and the Neck Pain and Disability Scale. Spine. 2007 Dec 15;32(26):E825-31.

17. O'Sullivan C, Meaney J, Boyle G, Gormley J, Stokes M. The validity of rehabilitative ultrasound imaging for measurement of trapezius muscle thickness. Manual therapy. 2009 Oct 1;14(5):572-8.

18. Hammer WI. The effect of mechanical load on degenerated soft tissue. J Bodyw Mov Ther. 2008 Jul 1;12(3):246-56.

19. Gulick DT. Instrument-assisted soft tissue mobilization increases myofascial trigger point pain threshold. J Bodyw Mov Ther. 2018 Apr 1;22(2):341-5.

20. Chou LW, Kao MJ, Lin JG. Probable mechanisms of needling therapies for myofascial pain control J Evid Based Complementary Altern Med. 2012:705327.

21. Melzack R. Myofascial trigger points: relation to acupuncture and mechanisms of pain. Arch Phys Med Rehabil. 1981 Mar;62(3):114-7.

22. Chen JT, Chung KC, Hou CR, Kuan TS, Chen SM, Hong CZ. Inhibitory effect of dry needling on the spontaneous electrical activity recorded from myofascial trigger spots of rabbit skeletal muscle. Am J Phys Med Rehabil. 2001 Oct 1;80(10):729-35.

23. Rodríguez-Mansilla J, González-Sánchez B, García ÁD, ValeraDonoso E, Garrido-Ardila EM, Jimenez-Palomares M, López-Arza MV. Effectiveness of dry needling on reducing pain intensity in patients with myofascial pain syndrome: a Meta-analysis. J Tradit Chinese Medical Sci. 2016 Feb 15;36(1):1-3.

24. Dommerholt J. Dry needling in orthopedic physical therapy practice. Orthop Phys Ther Pract. 2004;16(3):15-20. 47

25. Dommerholt J, Huijbregts P. Myofascial trigger points: pathophysiology and evidence-informed diagnosis and management. Jones \& Bartlett Learning; 2010 Oct 22.

26. Ga H, Choi JH, Park CH, Yoon HJ. Dry needling of trigger points with and without paraspinal needling in myofascial pain syndromes in elderly patients. J Altern Complement Med. 2007 Aug 1;13(6):61724.

27. Tsai CT, Hsieh LF, Kuan TS, Kao MJ, Chou LW, Hong CZ. Remote effects of dry needling on the irritability of the myofascial trigger point in the upper trapezius muscle. Am J Phys Med Rehabil. 2010 Feb 1;89(2):133-40

28. Rayegani SM, Bayat M, Bahrami MH, Raeissadat SA, Kargozar E. Comparison of dry needling and physiotherapy in treatment of myofascial pain syndrome. Clin Rheumatol. 2014 Jun 1;33(6):859-64.
29. Doğan N, Sengül İ, Akçay-Yalbuzdağ S, Kaya T. Kinesio taping versus dry needling in the treatment of myofascial pain of the upper trapezius muscle: A randomized, single blind (evaluator), prospective study. Back Musculoskelet Rehabil. 2019 Mar 1(Preprint):1-9.

30. Walsh R, Kinsella S, McEvoy J. The effects of dry needling and radial extracorporeal shockwave therapy on latent trigger point sensitivity in the quadriceps: A randomised control pilot study. J Bodyw Mov Ther. 2019 Jan 1;23(1):82-8.

31. Gulick DT. Influence of instrument assisted soft tissue treatment techniques on myofascial trigger points. J Bodyw Mov Ther. 2014 Oct 1;18(4):602-7. 